\title{
Glypican-3 (GPC3) is associated with MCPyV-negative status and impaired outcome in
}

\section{Merkel Cell Carcinoma}

Sujatha Muralidharan ${ }^{1 *}$, Thibault Kervarrec ${ }^{2 *}$, Glen J. Weiss $^{1 * *}$, Mahtab Samimi $^{2 * *}$

${ }^{1}$ SOTIO Biotech Inc., Cambridge, MA 02140

${ }^{2}$ University Hospital of Tours, Tours, France 37170

*Contributed equally to this work

**Corresponding authors: Glen J. Weiss, SOTIO Biotech Inc., 200 Cambridgepark Dr. Ste

3000, Cambridge, MA 02140 Phone: 617-904-7600 Email: weiss@ sotio.com

Mahtab Samimi, MD PhD, Department of Dermatology, University Hospital of Tours,

France; ISP1282 INRA University of Tours, France; Phone: +33247474625 Email:

mahtab.samimi@univ-tours.fr

Word count: 2,283, 2 tables, 2 figures, 1 supplementary table, and 1 supplementary figure

Keywords: Merkel cell carcinoma, glypican-3, Merkel cell polyomavirus, outcome

This work was funded by SOTIO Biotech Inc. 


\begin{abstract}
Background

Merkel cell carcinoma (MCC) is an aggressive skin cancer, related to the Merkel Cell Polyomavirus (MCPyV) in $80 \%$ of cases. Immune checkpoint inhibitors provide sustained benefit in about half of MCC patients with advanced disease. Glypican-3 (GPC3) is an oncofetal tumor antigen that is an attractive target for chimeric antigen receptor $\mathrm{T}$ cell therapy due to its highly restricted expression on normal tissue and high prevalence in several solid tumors. GPC3 was previously found to be expressed in MCC but its association with tumor characteristics or prognosis has not been reported.
\end{abstract}

\title{
Objectives
}

To investigate the expression of GPC3 in MCC by immunohistochemistry (IHC) and its association with tumor characteristics, MCPyV status, and patient outcome.

\section{Methods}

The GC33 antibody clone was validated for GPC3 IHC staining of tumor specimens in comparison to an established GPC3 IHC antibody. A tissue microarray of tumors collected from an ongoing cohort of MCC patients was stained for GPC3 by IHC using GC33 antibody. Association of GPC3 positivity with baseline characteristics, MCPyV status (quantitative PCR) and outcome (death from MCC, recurrence) were assessed by Fisher's exact tests and Cox regression analysis.

\section{Results}

Among 62 tumors from 59 patients, 42 samples (67.7\%) were GPC3-positive. GPC3 expression was more frequently observed in females $(\mathrm{p}=0.048)$ and MCPyV-negative tumors $(\mathrm{p}=0.021)$. In the multivariate analysis, GPC3 expression was associated with increased death from disease (CSS) (hazard ratio [HR] 4.05, 95\% CI 1.06-15.43), together with advanced age (HR 4.85, 95\% CI 1.39-16.9) and male gender (HR 4.64, 95\% CI 1.31-16.41). 
bioRxiv preprint doi: https://doi.org/10.1101/2022.02.06.479301; this version posted February 9, 2022. The copyright holder for this preprint (which was not certified by peer review) is the author/funder. All rights reserved. No reuse allowed without permission.

\section{Conclusions}

GPC3 expression is frequently expressed in MCC tumors, especially MCPyV-negative cases, and is associated with increased risk of death. The high prevalence of surface GPC3 makes it a putative drug target. 


\section{INTRODUCTION}

Merkel cell carcinoma (MCC) is a rare and aggressive neuroendocrine skin cancer mostly occurring in elderly patients, with increased incidence in case of immunosuppression(1). MCC has a high propensity to metastasize, and the five-year overall survival has been estimated at $40 \%(2)$. While $80 \%$ of MCC are related to the integration of the oncogenic Merkel Cell Polyomavirus (MCPyV) genome into host cells(3), the remaining 20\% cases are MCPyV-negative and harbor UV-induced mutations disrupting several oncogenic pathways(4). Both subsets were found to be immunogenic leading to the rationale of treating advanced stage MCC with immune checkpoint inhibitors (ICIs) such as PD-1/PD-L1 inhibitors. ICIs are considered a standard of care in patients with advanced disease(5,6). More than half of patients experience primary or secondary resistance to ICIs, which underlines the need for additional therapies, either as monotherapy or exerting synergistic effect with $\operatorname{ICIs}(7)$.

Glypican-3 (GPC3) is an oncofetal tumor antigen that is an attractive target for chimeric antigen receptor (CAR) T cell therapy due to its highly restricted expression on normal tissue and high prevalence in several adult and pediatric solid tumors(8). Aberrant GPC3 expression is implicated in tumorigenesis, and GPC3+ cancers are characterized by a highly immunosuppressive landscape which induces exhaustion in tumor-resident T cells(8). Drugs targeting GPC3 have been assessed in advanced cancer(9). GPC3 was previously found to be expressed in neuroendocrine small cell carcinomas including $\mathrm{MCC}(10)$, but its association with tumor stage, MCPyV status, or prognosis has not been characterized. The aim of the present study was to complete validation of a GPC3 antibody for use in immunohistochemistry (IHC), investigate the expression of GPC3 in MCC by IHC and to assess its association with tumor characteristics, MCPyV status, and patient outcome. 
bioRxiv preprint doi: https://doi.org/10.1101/2022.02.06.479301; this version posted February 9, 2022. The copyright holder for this preprint (which was not certified by peer review) is the author/funder. All rights reserved. No reuse allowed without permission. 


\section{MATERIAL AND METHODS}

\section{Patients and tumor samples}

MCC cases were selected from an ongoing historical/prospective cohort of MCC patients from France (local ethics committee approval, Tours, France, no. RCB2009-A01056-51) whose settings and inclusion criteria have previously been reported(11). Age, sex, American Joint Committee on Cancer (AJCC) stage at the time of diagnosis, immunosuppression (HIV infection, organ transplant recipients, hematological malignancies) and follow-up data (recurrence, death of any cause, death from MCC) were collected from patient files. Death was categorized as being related to MCC (CSS, cancer-specific death) or not (other cause) based on patients' medical files. CSS was defined as the time from the initial confirmed diagnosis of MCC to the date of death related to MCC; overall survival (OS) as the time from diagnosis to the date of death regardless of cause; recurrence-free survival (RFS) as the time from diagnosis to the date of a clinical or paraclinical event related to MCC recurrence. Tumor samples had been collected during routine biopsies or surgeries as part of patients' treatment plan.

Tumor samples were included in a tissue microarray (TMA), as previously described(11). Briefly, intratumor areas without necrosis were selected on hematoxylin phloxin saffronstained before being extracted using a 1-mm tissue core, and cores were mounted in triplicate on the tissue microarray by using a semi-motorized tissue array system (MTA booster OI v2.00, Alphelys).

Twenty unique MCC whole mount specimen FFPE blocks (without clinical annotation) were sourced independently from AMS Bio. For GPC3 IHC validation with GC33 antibody, FFPE blocks for hepatocellular carcinoma (HCC), liposarcoma and non-small cell lung cancer (NSCLC) were sourced by NeoGenomics Laboratories, Inc. (Aliso Viejo, CA) from DLS and 
ProteoGenex. A normal tissue TMA consisting of different organ specimens from 3 unique individuals was sourced from US Biomax (Cat\# FDA999w1).

\section{Determination of MCPyV status}

MCPyV status was determined in MCC tumors using real time quantitative PCR as previously described. Briefly, genomic DNA was isolated from tumor samples and LTAg real-time PCR assay was performed using previously reported primers(11). Normalization was with albumin as the reference gene and the Waga MCC cell line (RRID:CVCL E998) was included as a control. The $\Delta \mathrm{Ct}$ method was used for quantification and results expressed as number of MCPyV copies/cells. MCPyV-positivity was defined for cases harboring MCPyV load >1.2 copies/cell(11).

\section{IHC assessment of GPC3}

FFPE sections at $5 \mu \mathrm{m}$ were stained using anti-GPC3 mouse monoclonal primary antibody clone GC33 (Ventana Medical Systems, Inc. Tucson, AZ Cat\# 790-45654) on BenchMark ULTRA to detect membrane and cytoplasmic expression. After anti-GPC3 primary antibody staining, heat-induced epitope retrieval was used followed by incubation of the primary antibody for 32 minutes. Immunodetection was accomplished with OptiView DAB Detection Kit (Ventana, Cat\# 760-700). Isotype negative control and H\&E staining was included for each specimen. Batch positive and negative controls were included on each stain run. Stained images were examined by a pathologist (MS) who was blinded to clinical data. In some cases, strong cytoplasmic staining complicated the ability to report strictly membrane staining as an individual compartment, therefore the final scoring of the tumor cells combined both cytoplasmic and membranous staining. Percent of tumor cells with GPC3 membrane and cytoplasmic staining at each intensity $(0,1+, 2+, 3+$ corresponding to no staining, weak staining, moderate staining, and strong staining; respectively) were recorded and an overall Hscore was calculated (range 0-300). 
For validation of antibody clone GC33 for GPC3 IHC staining as a lab-developed test, all tumor tissue samples were stained with GC33 or 1G12 (a GPC3 IHC antibody clone used as an in vitro diagnostic and previously validated by NeoGenomics) and accuracy, sensitivity, specificity and precision of GC33 was determined compared to 1G12. Using comparisons between the 2 assays as a standard curve, a cutoff of H-score >30 for the GC33 was most comparable to a cutoff of $\mathrm{H}$-score $>20$ as established for the $1 \mathrm{G} 12$ assay to report Positive or Negative for GPC3 expression (Figure S1). Specimens that showed consistent positive or negative results by both GC33 and 1G12 were considered true positive (TP) and true negative (TN) respectively. Any specimen reported positive by GC33 stain but negative by 1 G12 or negative by GC33 but positive by $1 \mathrm{G} 12$ were considered false positive (FP) or false negative (FN) respectively. Accuracy was determined by comparing observed GC33 true staining to total specimens stained $(\mathrm{TP}+\mathrm{TN} /$ Total specimens $)$. Sensitivity was evaluated by comparing the observed GC33 true positive staining of the specimens to the expected positive expression $(\mathrm{TP} / \mathrm{TP}+\mathrm{FN})$. Specificity was evaluated by comparing the observed GC33 true negative staining of the specimens to the expected negative expression $(\mathrm{TN} / \mathrm{TN}+\mathrm{FP})$. Precision was determined by repeat staining of select specimens and examining concordance of results between repeat runs.

For MCC prevalence determination in terms of GPC3 protein expression by IHC, results from the validated GC33 assay were used. Interpretation of all immunostainings was blinded from clinicopathological parameters and patient outcome. When patients had more than one tumor sample included in the MCC TMA (for instance, primary tumor and metastasis), the GPC3 scoring of the primary tumor was included in the baseline and outcome analysis. 


\section{Statistical analyses}

Continuous data are described by medians (Q1-Q3) and categorical data with number and percentage of interpretable cases. Associations were assessed by two-tailed Fisher's exact tests for categorical data. RFS, OS and CSS were analyzed by log-rank tests and presented as Kaplan-Meier curves. Univariate and multivariate Cox proportional-hazards regression was used to identify factors associated with outcome, estimating hazard ratios (HRs) and 95\% confidence intervals (CIs). Covariates were identified as potential prognostic confounders with $\mathrm{p} \leq 0.25$ on Cox univariate regression analysis and then included in the multivariate Cox analysis. $\mathrm{P}<0.05$ was considered statistically significant. Statistical analysis involved use of XL-Stat-Life (Addinsoft, Paris, France). 


\section{RESULTS}

\section{Validation of GPC3 IHC using GC33 in MCC specimens}

In order to validate the GPC3 IHC assay using GC33 antibody for use as a lab-developed test for clinical trials, TMA slides or whole mount slides containing tumor samples from HCC, liposarcoma, lung cancer, and MCC patients were stained by GPC3 IHC assays using either GC33 or previously validated 1G12 antibody clones. Scoring of these specimens based on GC33 vs. 1G12 staining was used to determine true and expected GPC3 expression (Table S1). These values were used to calculate accuracy, sensitivity, specificity and precision of GC33 staining for GPC3 compared to comparator 1G12 staining in tumor specimens for the purposes of GC33 assay validation. The GC33 assay was fully validated for use as a labdeveloped test as it met all acceptable criteria (accuracy: 95\%; sensitivity: 100\%; specificity: 92\%; precision: 100\%) for each of these parameters and we used this assay for further assessments of MCC patient specimens.

\section{GPC3 expression in MCC and baseline characteristics}

We examined MCC samples as well as normal tissue including skin for basal expression, using GPC3 GC33 IHC (Fig. 1). GPC3 was absent in normal skin. Among the $68 \mathrm{MCC}$ tumors included in the TMA, 62 had at least one interpretable core for GPC3 staining (one core $n=8$, two cores $n=25$, three cores $n=29$ ). The median immunohistochemical GPC3 score was 85.8 (Q1-Q3 2.5-138.3, ranges 0-285) and accordingly, 42/62 samples (67.7\%) were defined as GPC3-positive with an H-score >30. Representative IHC results are shown in Fig. 1. Among the 3 patients who had two tumor samples included in the TMA (primary tumor and lymph node metastasis), GPC3 expression was concordant between the primary tumor and the lymph node metastasis in two cases (both positive, $n=1$; both negative, $n=1$ ) and discordant in one case, where GPC3 expression was negative in the primary tumor and positive in the lymph node metastasis. Overall, 59 unique patients with MCC were included in 
the analysis reported in Table 1. GPC3 expression was more frequently expressed in female $(27 / 35,77 \%)$ than male patients $(12 / 23,52 \%)(\mathrm{p}=0.048)$ and in MCPyV-negative $(11 / 12$, 92\%) than MCPyV-positive tumors $(26 / 44,59 \%)(\mathrm{p}=0.021)$. GPC3 expression was not associated with age, location of primary tumor, AJCC stage on diagnosis, type of tumor specimen (primary or metastasis), or immunosuppression (Table 1).

\section{Independent cohort of MCC samples}

In evaluation of the independent cohort of whole mount MCC samples $(n=20)$ with the GPC3 GC33 IHC assay, 14 samples showed positive GPC3 expression (H score >30) indicating a prevalence of $70 \%$ GPC3 positive cases in MCC. This was consistent with the GPC3+ prevalence determination based on MCC cases from the TMA.

\section{GPC3 expression and patient outcome}

Data were available for 59 patients, with a median follow up of 87.7 months (95\% CI 74.097.5). Mean OS was 67.7 months (95\% CI 53.7-81.7) and mean CSS was 85.0 months (95\% CI 70.3-99.6). During follow up, 23 patients had recurred (38.9\%) and 32 patients (54.2\%) had died including 19 from MCC (59.3\%). As shown in Fig. 2, five-year CSS was numerically higher in GPC3-negative than GPC3-positive patients (77.2\%, 95\% CI 57.3-97.0 vs $57.1 \%, 95 \%$ CI 40.6-73.6) (log-rank test, $\mathrm{p}=0.142$ ). OS and RFS did not differ significantly between groups (Fig. 2). In the multivariate analysis, GPC3 expression was associated with worse CSS (HR 4.05, 95\% CI 1.06-15.43), together with advanced age (HR 4.85, 95\% CI 1.39-16.9) and male gender (HR 4.64, 95\% CI 1.31-16.41). By contrast, MCPyV-positive MCC cases were associated with reduced risk of death (HR $0.37,95 \%$ CI $0.00-0.83$ ) and reduced risk of recurrence (HR $0.20,95 \%$ CI $0.00-0.57$ ). GPC3 had no significant association with OS, while advanced age (HR 3.85, 95\% CI 1.52-9.48), male gender (HR 2.75, 95\% CI 1.10-6.84), and immunosuppression (HR 5.25, 95\% CI 1.82-15.2) were associated with worse OS. 


\section{DISCUSSION}

In this study, we found that GPC3 was expressed in nearly $70 \%$ of MCC tumors and up to $90 \%$ of MCPyV-negative cases, and was associated with worse prognosis in terms of risk of death from MCC. GPC3 is an heparan sulfate proteoglycan which is expressed in embryonic tissues and solid cancers such as hepatocellular carcinoma, ovarian clear cell carcinoma, melanoma, squamous cell carcinoma of the lung, and some pediatric cancers(9). GPC3 was not expressed in normal skin in our samples, similar to other results(12). Our results are in line with one previous study which reported increased GPC3 in MCC at the transcriptional level(13). Another study reported GPC3 expression by IHC in 39 out of $55 \mathrm{MCC}$ cases (71\%), without providing details on tumor characteristics or clinical outcomes(10). In our study, GPC3 expression was associated with death from MCC, in line with reports of its prognostic role in hepatocellular carcinoma(14). Indeed, GPC3 was reported to participate in tumor growth and promote epithelial-mesenchymal transition by impacting several signaling pathways, such as upregulation of the Wnt signaling, ERK pathway, YAP and hedgehog cascades(15). In the setting of MCC, the significant differential expression with MCPyVpositive and $\mathrm{MCPyV}$-negative remains elusive, given that little is known on the regulation of GPC3 expression. Although no GPC3 mutations have been identified so far in MCPyVnegative MCCs, GPC3 was shown to be a transcriptional target of c-Myc in the setting of hepatocellular carcinoma(16). Interestingly, MYC family gene amplification and MYC protein expression have previously been reported in virus-negative MCCs(17-19). On the other hand, the MCPyV oncoprotein ST forms a complex with the MYC paralog MYCL (L-MYC) and its heterodimeric partner MAX, the complex recruiting EP400 chromatin remodeling complex, which in turn bind to the transcriptional start sites of several hundred target genes, which encompass a large number of known MYC target genes(20). 
Limitations to our study include a small cohort of predominantly early-stage MCC and that this was a retrospective analysis. Additional independent clinical prevalence studies in advanced MCC are needed to validate our findings.

In conclusion, GPC3 expression, advanced age, and male gender were associated with impaired CSS in MCC in this study, whereas MCPyV-positivity was significantly associated with reduced risk of death and recurrence. Given its high prevalence in MCC and restricted expression in normal tissue, GPC3 is an attractive target for CAR T cell therapy. The GC33 clone performs similarly to 1 G12 and will be used for IHC screening for clinical trials. A new CAR T trial evaluating a GPC3 directed CAR T in patients with solid tumors including MCC is due to activate (NCT05120271). 
Acknowledgements. Authors acknowledge dermatologists and pathologists who included patients in the MCC cohort (Drs. Guido Bens, Eric Estève, and Patrick Michenet, CHR Orléans, France; Drs. Yannick Le Corre and Sophie Michalak-Provost, CHU Angers, France; Prof. François Aubin and Dr. Charlée Nardin, CHU Besançon, France; Drs. Ewa Wierzbiecka-Hainault and Eric Frouin, CHU Nantes, France; Prof. Philippe Saïag and Dr. Astrid Blom, Hospital Ambroise Paré, Paris, France; and Anne Tallet (Plateforme de Génétique Moléculaire des Cancers, CHU Tours, France) who performed the qPCR analyses. 


\section{References}

1. Harms PW, Harms KL, Moore PS, DeCaprio JA, Nghiem P, Wong MKK, et al. The biology and treatment of Merkel cell carcinoma: current understanding and research priorities. Nat Rev Clin Oncol [Internet]. 2018 Dec 1 [cited 2022 Jan 13];15(12):76376. Available from: https://pubmed.ncbi.nlm.nih.gov/30287935/

2. Harms KL, Healy MA, Nghiem P, Sober AJ, Johnson TM, Bichakjian CK, et al. Analysis of Prognostic Factors from 9387 Merkel Cell Carcinoma Cases Forms the Basis for the New 8th Edition AJCC Staging System. Ann Surg Oncol [Internet]. 2016 Oct 1 [cited 2022 Jan 13];23(11):3564-71. Available from: https://pubmed.ncbi.nlm.nih.gov/27198511/

3. Feng H, Shuda M, Chang Y, Moore PS. Clonal integration of a polyomavirus in human Merkel cell carcinoma. Science [Internet]. 2008 Feb 22 [cited 2022 Jan 13];319(5866):1096-100. Available from: https://pubmed.ncbi.nlm.nih.gov/18202256/

4. Goh G, Walradt T, Markarov V, Blom A, Riaz N, Doumani R, et al. Mutational landscape of MCPyV-positive and MCPyV-negative Merkel cell carcinomas with implications for immunotherapy. Oncotarget [Internet]. 2016 [cited 2022 Jan 13];7(3):3403-15. Available from: https://pubmed.ncbi.nlm.nih.gov/26655088/

5. Bichakjian CK, Olencki T, Aasi SZ, Alam M, Andersen JS, Blitzblau R, et al. Merkel Cell Carcinoma, Version 1.2018, NCCN Clinical Practice Guidelines in Oncology. J Natl Compr Canc Netw [Internet]. 2018 Jun 1 [cited 2022 Jan 13];16(6):742-74. Available from: https://pubmed.ncbi.nlm.nih.gov/29891526/

6. Becker JC, Eigentler T, Frerich B, Gambichler T, Grabbe S, Höller U, et al. S2k guidelines for Merkel cell carcinoma (MCC, neuroendocrine carcinoma of the skin) update 2018. J Dtsch Dermatol Ges [Internet]. 2019 May 1 [cited 2022 Jan 13];17(5):562-76. Available from: https://pubmed.ncbi.nlm.nih.gov/31056838/ 
7. Samimi M. Immune Checkpoint Inhibitors and Beyond: An Overview of ImmuneBased Therapies in Merkel Cell Carcinoma. Am J Clin Dermatol [Internet]. 2019 Jun 1 [cited 2022 Jan 13];20(3):391-407. Available from: https://pubmed.ncbi.nlm.nih.gov/30784027/

8. Hickman TL, Choi E, Whiteman KR, Muralidharan S, Pai T, Johnson T, et al. BOXR1030, an anti-GPC3 CAR with exogenous GOT2 expression, shows enhanced T cell metabolism and improved antitumor activity. bioRxiv [Internet]. 2021 Nov 19 [cited 2022 Jan 13];2021.11.17.469041. Available from: https://www.biorxiv.org/content/10.1101/2021.11.17.469041v1

9. Shimizu Y, Suzuki T, Yoshikawa T, Endo I, Nakatsura T. Next-Generation Cancer Immunotherapy Targeting Glypican-3. Front Oncol [Internet]. 2019 [cited 2022 Jan 13];9(APR). Available from: https://pubmed.ncbi.nlm.nih.gov/31024850/

10. He H, Fang W, Liu X, Weiss LM, Chu PG. Frequent expression of glypican-3 in Merkel cell carcinoma: an immunohistochemical study of 55 cases. Appl Immunohistochem Mol Morphol AIMM [Internet]. 2009 Jan [cited 2022 Jan 13];17(1):40-6. Available from: https://pubmed.ncbi.nlm.nih.gov/18813128/

11. Kervarrec T, Tallet A, Miquelestorena-Standley E, Houben R, Schrama D, Gambichler T, et al. Diagnostic accuracy of a panel of immunohistochemical and molecular markers to distinguish Merkel cell carcinoma from other neuroendocrine carcinomas. Mod Pathol [Internet]. 2019 Apr 1 [cited 2022 Jan 13];32(4):499-510. Available from: https://pubmed.ncbi.nlm.nih.gov/30349028/

12. Al-saraireh Y, Alrawashdeh F, Al-shuneigat J, Alsbou M, Alnawaiseh N, Al-shagahin $\mathrm{H}$, et al. Screening of Glypican- 3 Expression in Human Normal versus Benign and Malignant Tissues: A Comparative Study Glypican- 3 expression in cancers. Biosci Biotechnol Res Asia [Internet]. 2016 Jun 28 [cited 2021 Oct 8];13(2):687-92. 
Available from: http://www.biotech-asia.org/vol13no2/screening-of-glypican-3expression-in-human-normal-versus-benign-and-malignant-tissues-a-comparativestudy-glypican-3-expression-in-cancers/

13. Harms PW, Patel RM, Verhaegen ME, Giordano TJ, Nash KT, Johnson CN, et al.

Distinct gene expression profiles of viral- and nonviral-associated merkel cell carcinoma revealed by transcriptome analysis. J Invest Dermatol [Internet]. 2013 [cited 2022 Jan 13];133(4):936-45. Available from:

https://pubmed.ncbi.nlm.nih.gov/23223137/

14. Zhang J, Zhang M, Ma H, Song X, He L, Ye X, et al. Overexpression of glypican-3 is a predictor of poor prognosis in hepatocellular carcinoma: An updated meta-analysis.

Medicine (Baltimore) [Internet]. 2018 Jun 1 [cited 2022 Jan 13];97(24). Available

from: https://pubmed.ncbi.nlm.nih.gov/29901640/

15. Kolluri A, Ho M. The Role of Glypican-3 in Regulating Wnt, YAP, and Hedgehog in Liver Cancer. Front Oncol [Internet]. 2019 Aug 2 [cited 2022 Jan 13];9. Available from: https://pubmed.ncbi.nlm.nih.gov/31428581/

16. Li L, Jin R, Zhang X, Lv F, Liu L, Liu D, et al. Oncogenic activation of glypican-3 by c-Myc in human hepatocellular carcinoma. Hepatology [Internet]. 2012 Oct [cited 2022 Jan 13];56(4):1380-90. Available from: https://pubmed.ncbi.nlm.nih.gov/22706665/

17. Horny K, Gerhardt P, Hebel-Cherouny A, Wülbeck C, Utikal J, Becker JC. Mutational Landscape of Virus- and UV-Associated Merkel Cell Carcinoma Cell Lines Is Comparable to Tumor Tissue. Cancers (Basel) [Internet]. 2021 Feb 2 [cited 2022 Jan 13];13(4):1-16. Available from: https://pubmed.ncbi.nlm.nih.gov/33562873/

18. González-Vela M del C, Curiel-Olmo S, Derdak S, Beltran S, Santibañez M, Martínez N, et al. Shared Oncogenic Pathways Implicated in Both Virus-Positive and UVInduced Merkel Cell Carcinomas. J Invest Dermatol [Internet]. 2017 Jan 1 [cited 2022 
Jan 13];137(1):197-206. Available from: https://pubmed.ncbi.nlm.nih.gov/27592799/

19. Knepper TC, Montesion M, Russell JS, Sokol ES, Frampton GM, Miller VA, et al. The Genomic Landscape of Merkel Cell Carcinoma and Clinicogenomic Biomarkers of Response to Immune Checkpoint Inhibitor Therapy. Clin Cancer Res [Internet]. 2019

Oct 1 [cited 2022 Jan 13];25(19):5961-71. Available from:

https://pubmed.ncbi.nlm.nih.gov/31399473/

20. Decaprio JA. Molecular Pathogenesis of Merkel Cell Carcinoma.

https://doi.org/101146/annurev-pathmechdis-012419-032817 [Internet]. 2021 Jan 26

[cited 2022 Jan 13];16:69-91. Available from:

https://www.annualreviews.org/doi/abs/10.1146/annurev-pathmechdis-012419-032817 
Table 1. GPC3 expression according to baseline characteristics.

\begin{tabular}{|c|c|c|c|c|}
\hline \multirow[t]{2}{*}{ Characteristics } & \multirow{2}{*}{$\begin{array}{l}\text { All patients } \\
\qquad \begin{array}{l}(n=59) \\
(n, \%)\end{array}\end{array}$} & \multicolumn{2}{|c|}{ GPC3 expression } & \multirow{2}{*}{$\begin{array}{l}\text { P-value } \\
\text { (Fisher's exact } \\
\text { test) }\end{array}$} \\
\hline & & $\begin{array}{c}\text { Negative }(n=20) \\
(n, \%)\end{array}$ & $\begin{array}{c}\text { Positive }(n=39) \\
(n, \%)\end{array}$ & \\
\hline $\begin{array}{l}\text { Age }(*) \\
>\text { median }(80.5 \mathrm{y}) \\
<\text { median }(80.5 \mathrm{y})\end{array}$ & $\begin{array}{l}29(50.0) \\
29(50.0)\end{array}$ & $\begin{array}{l}10(52.6) \\
9(47.4)\end{array}$ & $\begin{array}{l}19(48.7) \\
20(51.3)\end{array}$ & 0.780 \\
\hline $\begin{array}{l}\text { Sex }(*) \\
\text { Female } \\
\text { Male }\end{array}$ & $\begin{array}{l}35(60.3) \\
23(39.7)\end{array}$ & $\begin{array}{l}8(42.1) \\
11(57.9)\end{array}$ & $\begin{array}{l}27(69.2) \\
12(30.8)\end{array}$ & 0.048 \\
\hline $\begin{array}{l}\text { AJCC stage (at diagnosis) } \\
\text { Stage } 1 \\
\text { Stage } 2 \\
\text { Stage } 3 \\
\text { Stage } 4\end{array}$ & $\begin{array}{l}20(34.5) \\
19(32.8) \\
18(31.0) \\
1(1.7)\end{array}$ & $\begin{array}{l}8(42.1) \\
3(15.8) \\
8(42.1) \\
0(0.0)\end{array}$ & $\begin{array}{l}12(30.8) \\
16(41.0) \\
10(25.6) \\
1(2.6)\end{array}$ & 0.162 \\
\hline $\begin{array}{l}\text { Immunosuppression }(*) \\
\text { No } \\
\text { Yes }\end{array}$ & $\begin{array}{l}52(89.7) \\
6(10.3)\end{array}$ & $\begin{array}{l}17(89.5) \\
2(10.5)\end{array}$ & $\begin{array}{l}35(89.7) \\
4(10.3)\end{array}$ & 0.975 \\
\hline $\begin{array}{l}\text { Location of primary (*) } \\
\text { head and neck } \\
\text { limb } \\
\text { trunk }\end{array}$ & $\begin{array}{l}19(32.8) \\
28(48.3) \\
5(8.6)\end{array}$ & $\begin{array}{l}5(26.3) \\
10(52.6) \\
2(10.5)\end{array}$ & $\begin{array}{l}12(30.8) \\
16(41.0) \\
10(25.6)\end{array}$ & 0.897 \\
\hline
\end{tabular}




\begin{tabular}{|l|l|l|l|l|}
\hline occult primary & $6(10.3)$ & $2(10.5)$ & $1(2.6)$ & \\
\hline Type of sample & $41(69.5)$ & $13(65.0)$ & $28(71.8)$ & \\
Primary & $18(30.5)$ & $7(35.0)$ & $11(28.2)$ & \\
Metastasis & $12(21.4)$ & $1(5.3)$ & $11(29.7)$ & $\mathbf{0 . 0 2 1}$ \\
\hline MCPyV status (**) & $44(78.6)$ & $18(94.7)$ & $26(70.3)$ & \\
Negative & & & \\
\hline Positive & & & \\
\hline
\end{tabular}

(*) data missing for one patient ; (**) data missing for 3 patients 
Table 2. Univariate and multivariate Cox proportional hazard analysis for MCC related death, death from any cause et MCC recurrence

\begin{tabular}{|c|c|c|c|c|c|c|c|c|c|c|c|c|}
\hline \multirow[t]{3}{*}{ Covariate } & \multicolumn{4}{|c|}{ Cancer Specific survival } & \multicolumn{4}{|c|}{ Overall survival } & \multicolumn{4}{|c|}{ MCC Recurrence (any site) } \\
\hline & \multicolumn{2}{|c|}{ Univariate analysis } & \multicolumn{2}{|c|}{$\begin{array}{c}\text { Multivariate } \\
\text { analysis }\end{array}$} & \multicolumn{2}{|c|}{ Univariate analysis } & \multicolumn{2}{|c|}{$\begin{array}{c}\text { Multivariate } \\
\text { analysis }\end{array}$} & \multicolumn{2}{|c|}{ Univariate analysis } & \multicolumn{2}{|c|}{ Multivariate analysis } \\
\hline & $\begin{array}{c}\text { HR }(95 \% \\
\text { CI })\end{array}$ & $\mathbf{p}$ & $\begin{array}{c}\text { HR }(95 \% \\
\text { CI })\end{array}$ & $\mathbf{p}$ & $\begin{array}{c}\text { HR }(95 \% \\
\text { CI) }\end{array}$ & $\mathbf{p}$ & $\begin{array}{c}\text { aHR }(95 \% \\
\text { CI) }\end{array}$ & $\mathbf{p}$ & $\begin{array}{c}\text { HR }(95 \% \\
\text { CI) }\end{array}$ & $\mathbf{p}$ & $\begin{array}{c}\text { aHR (95\% } \\
\text { CI) }\end{array}$ & $\mathbf{p}$ \\
\hline Age (years) & & & & & & & & & & & & \\
\hline$>80.5$ vs $\leq 80.5$ & $\begin{array}{c}2.86(1.08- \\
7.54)\end{array}$ & 0.034 & $\begin{array}{c}4.85(1.39- \\
16.9)\end{array}$ & 0.013 & $\begin{array}{c}2.85(1.37- \\
5.95)\end{array}$ & 0.005 & $\begin{array}{c}3.85(1.56- \\
9.48)\end{array}$ & 0.003 & $\begin{array}{c}1.13(0.50- \\
2.56)\end{array}$ & 0.772 & $\begin{array}{c}0.75(0.26- \\
2.16)\end{array}$ & 0.590 \\
\hline Sex & & & & & & & & & & & & \\
\hline male vs female & $\begin{array}{c}1.99(0.81- \\
4.92)\end{array}$ & 0.135 & $\begin{array}{c}4.64(1.31- \\
16.41)\end{array}$ & 0.017 & $\begin{array}{c}1.43(0.71- \\
2.88)\end{array}$ & 0.321 & $\begin{array}{c}2.75(1.10- \\
6.84)\end{array}$ & 0.030 & $\begin{array}{c}1.94(0.85- \\
4.42)\end{array}$ & 0.113 & $\begin{array}{c}1.56(0.57- \\
4.28)\end{array}$ & 0.389 \\
\hline AJCC & & & & & & & & & & & & \\
\hline $3-4$ vs $1-2$ & $\begin{array}{c}1.82(0.73- \\
4.55)\end{array}$ & 0.196 & $\begin{array}{c}2.16(0.73- \\
6.35)\end{array}$ & 0.161 & $\begin{array}{c}0.90(0.42- \\
1.96)\end{array}$ & 0.800 & $\begin{array}{c}1.65(0.68- \\
3.98)\end{array}$ & 0.265 & $\begin{array}{c}1.41(0.60- \\
3.34)\end{array}$ & 0.431 & $\begin{array}{c}1.64(0.63- \\
4.28)\end{array}$ & 0.314 \\
\hline
\end{tabular}




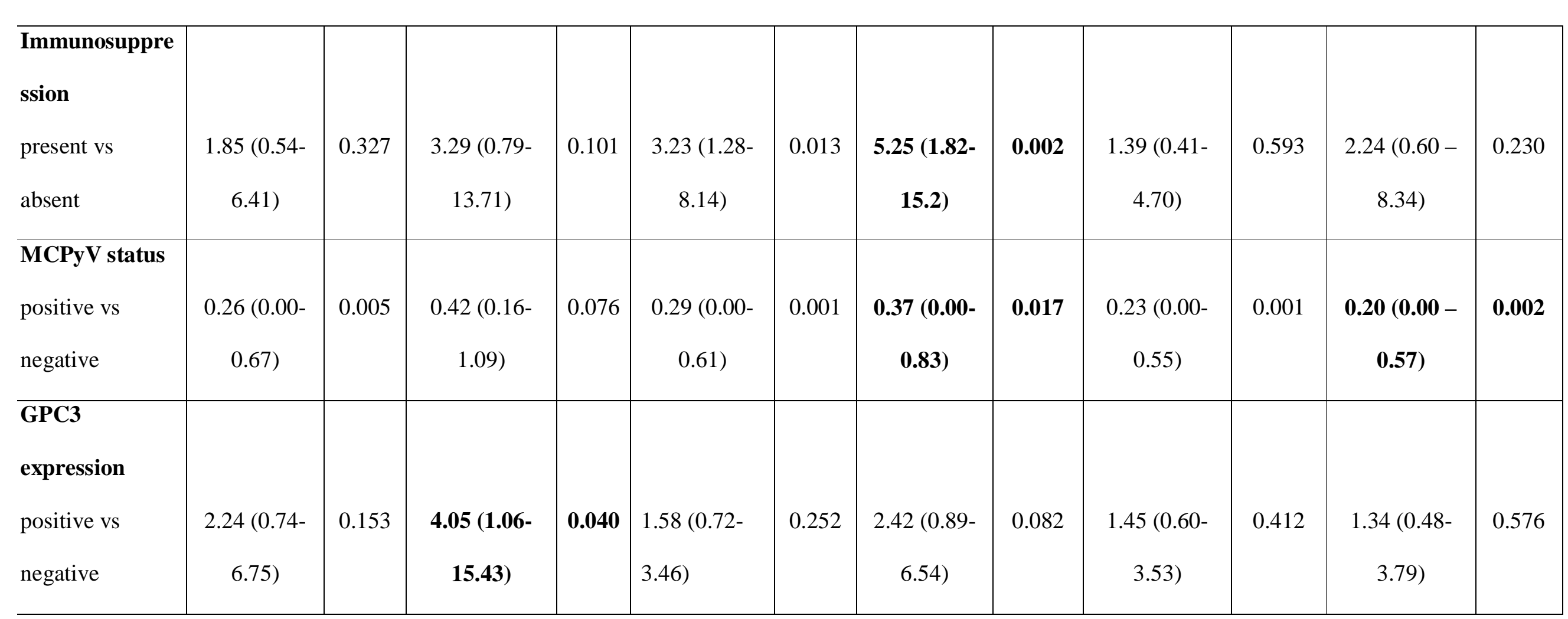

HR, Hazard Ratio, aHR, adjusted HR ; CI, confidence interval ; MCC, Merkel Cell Carcinoma 


\section{FIGURE LEGENDS}

Figure 1. Representative GPC3 expression by IHC: Immunohistochemical staining of (a) normal skin and (b) MCC tumors for GPC3 expression. Representative images (20x magnification) with different levels of GPC3 (and H-scores) are shown. The scale bar represents 200 $\mu \mathrm{m}$.

Figure 2. Kaplan Meier curves according to GPC3 expression: (a) Survival estimates of cancer-specific survival (CCS); (b) Survival estimate of overall survival (OS); and (c) Survival estimates of recurrence-free survival (RFS). Black bar: Positive GPC3 expression and grey bar: negative GPC3 expression.

Figure S1. Comparisons between the 2 IHC assays. Legend: $x$-axis is GC33, y-axis is 1G12, best fit lit is plotted with an $\mathrm{r}^{2}$ co-efficient of 0.9329. 
A.

Normal skin

H-Score: 0

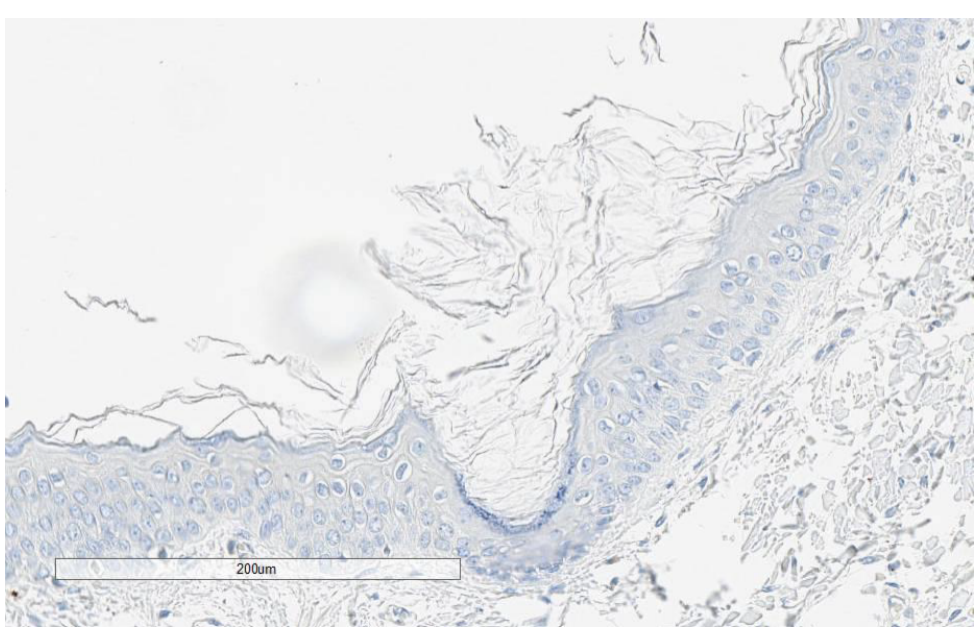

B.

MCC

H-Score: 30

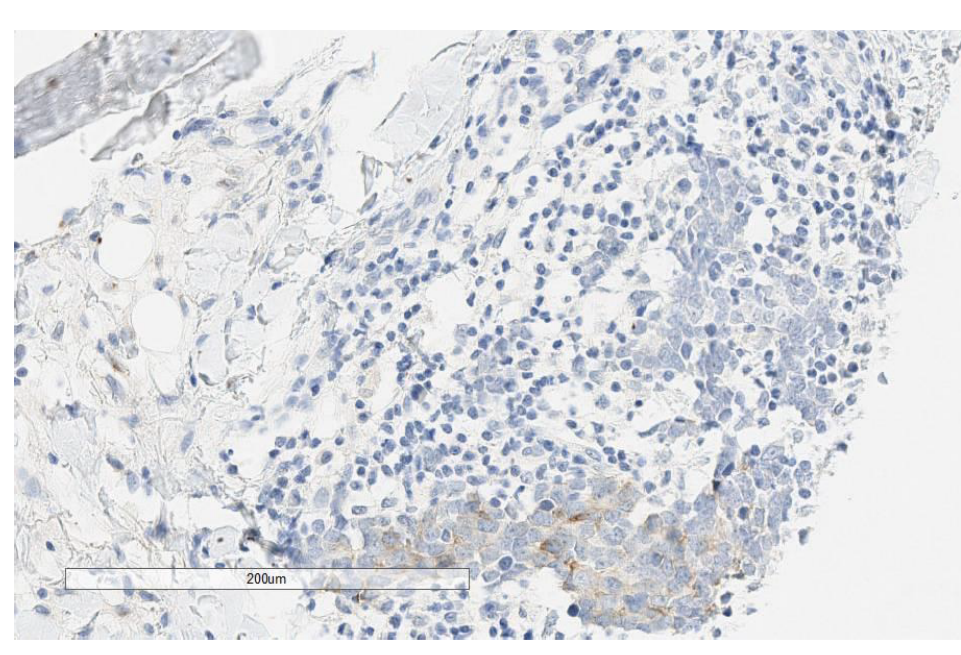

H-Score: 100

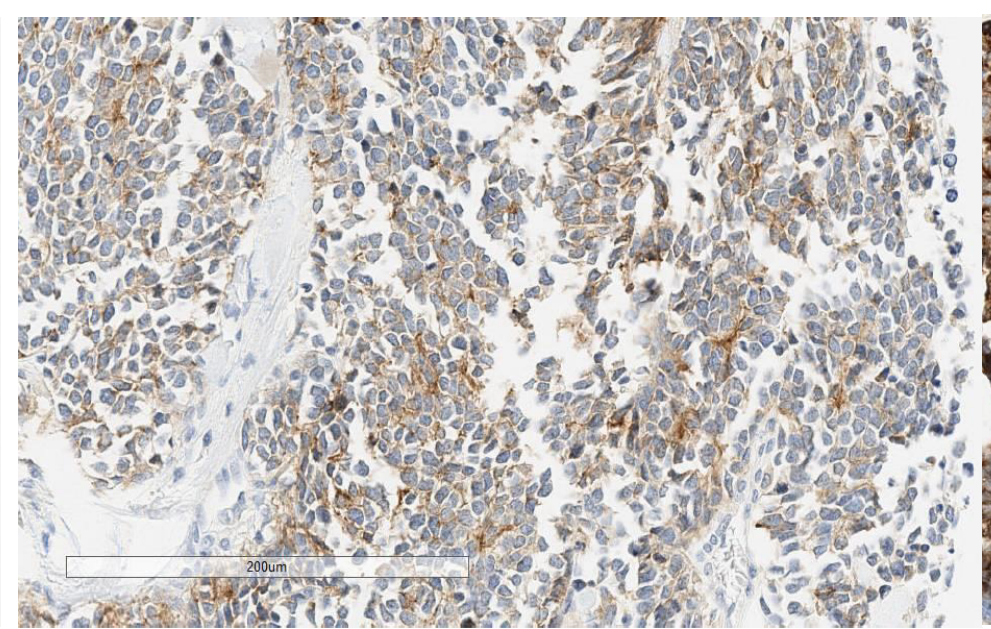

H-Score: 285

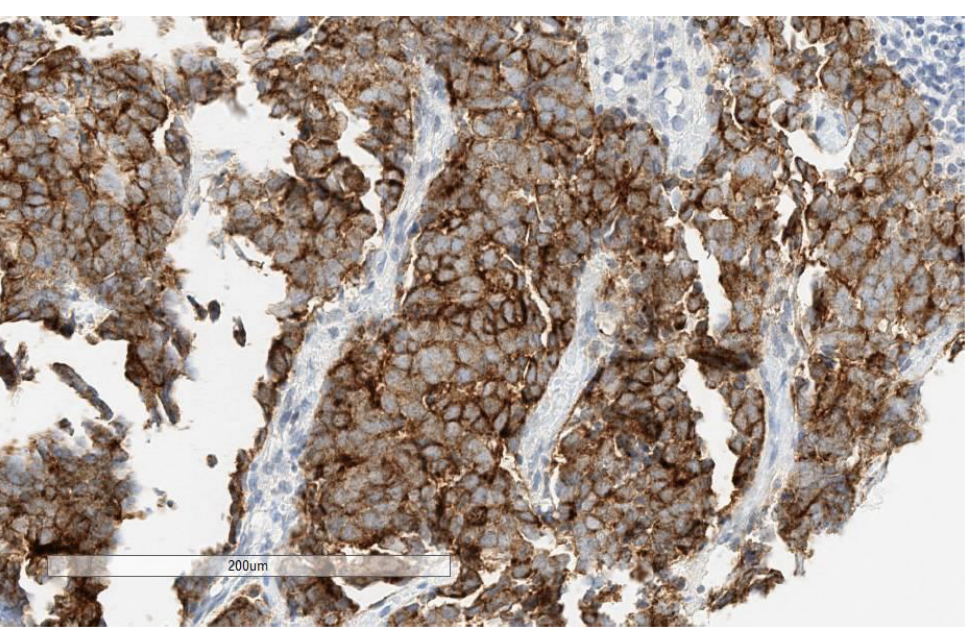


B

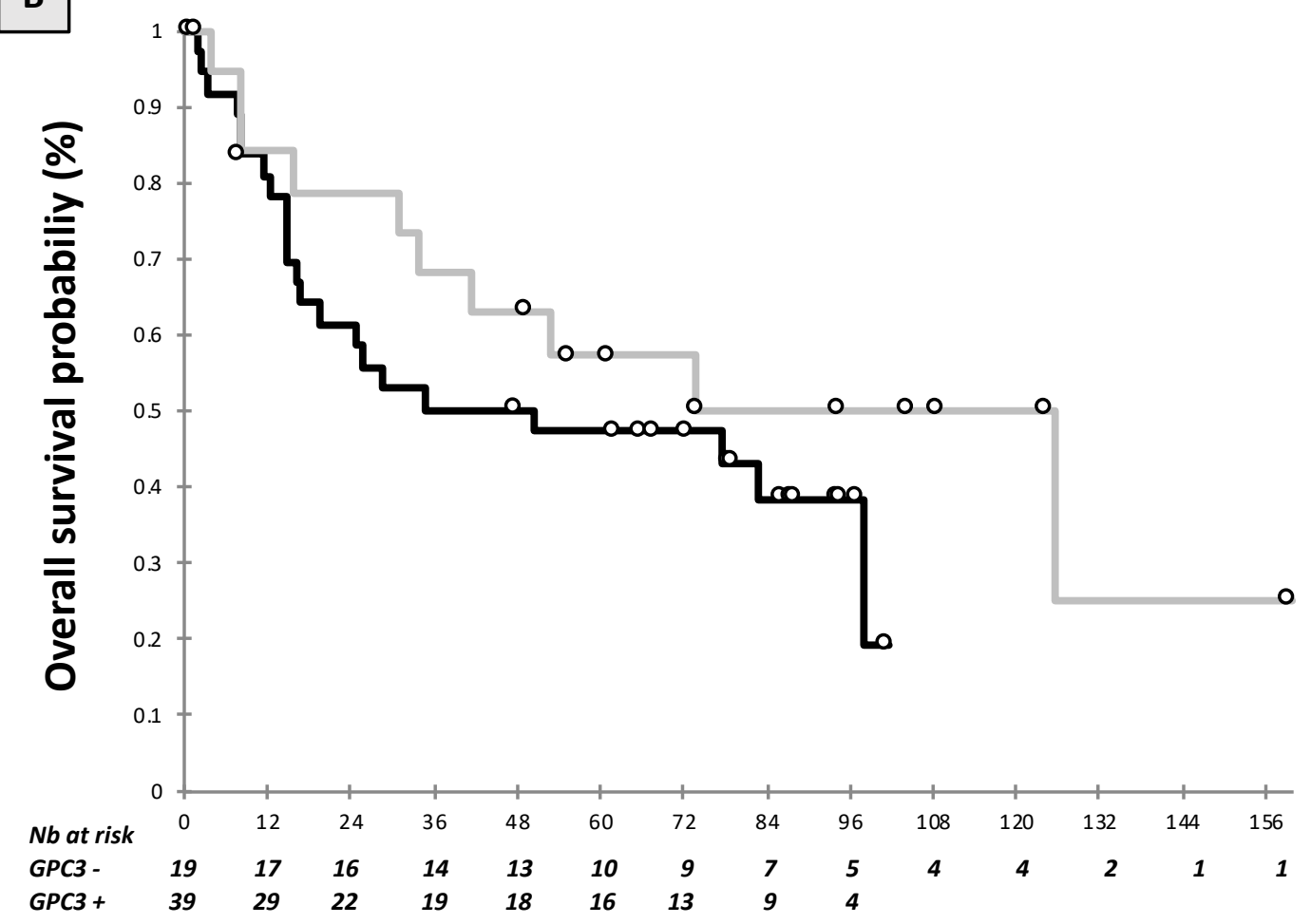

Log-rank test, $p=0.142$

C

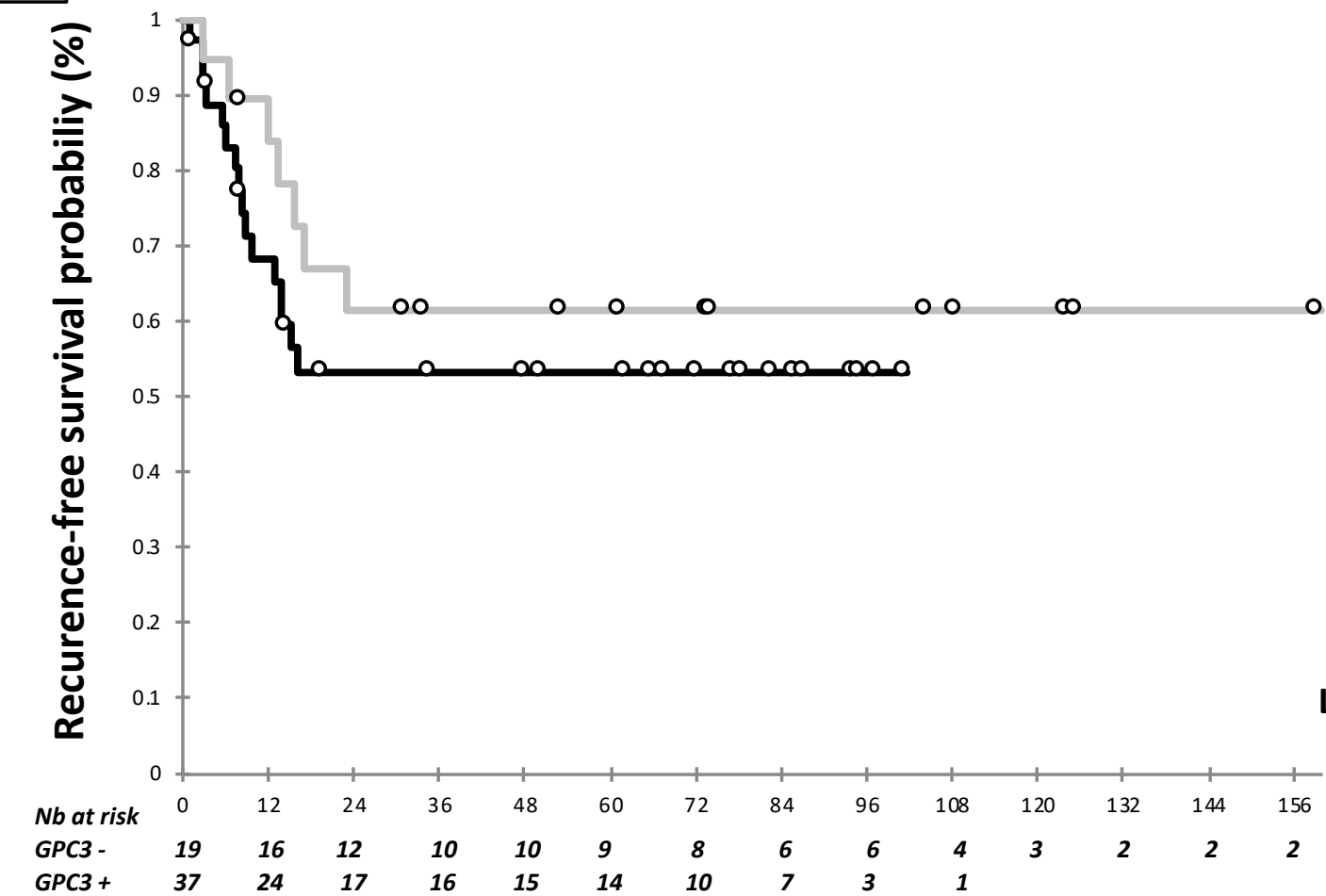

